\title{
MODELLING FORMATION AND DEVELOPMENT OF LONGITUDINAL CRACKS IN CONCRETE CROSSING CORRODING REINFORCEMENT
}

\author{
Vidmantas Jokūbaitis, Arvydas Jurkša \\ Dept of Reinforced Concrete and Masonry Structures, Vilnius Gediminas Technical University, \\ Sauletekio al. 11,LT-2040Vilnius, Lithuania.E-mail: gelz@st.vtu.lt \\ Received 18 Apr 2001; accepted 12 June 2002
}

\begin{abstract}
Tensile stresses in concrete occur under the action of reinforcement rust pressure. When they exceed concrete tensile strength or concrete extension strain exceeds limit value, concrete cracks. Physical and numerical models of such cracks are proposed for analysis of formation and development based on the main assumption that in the place of the rusting bar there is an artificial cut of circular shape, the contour of which is subjected to a pressure, imitating pressure of rust. Limit pressure values and character of formation and development of cracks through concrete cover to reinforcement are compared with data of experimental investigations performed by S.Williamson. The analysis has indicated that proposed models of formation and development of longitudinal concrete cracks are based on correct assumptions and can be applied for assessing the state of cracked reinforced concrete structures.
\end{abstract}

Keywords: reinforcement corrosion, pressure of corrosion products, longitudinal concrete cracks, physical and numerical model.

\section{Introduction}

Longitudinal cracks in concrete crossing reinforcement can be frequently observed in reinforced concrete structures. One of the main reasons of formation and development of such cracks is the steel reinforcement corrosion. Due to the electrochemical corrosion under the aggressive environment thickness or rust layer round reinforcing bar increases. Under the pressure of corrosion products tensile stresses develop in concrete. Concrete cracks if value of this stress at reinforcing bar exceeds concrete resistance or concrete extension exceeds limit value. Only a few investigations of formation and development of such cracks were carried out [1]. Influence of steel corrosion on reinforcement and concrete bond strength was investigated more deeply in [2-4]. Reinforcement corrosion process depends on many factors, including concrete cover quality and reinforcement bar diameter $[5,6]$.

On the basis of results of experimental and analytical examinations of formation and development of longitudinal cracks it is possible to introduce recommendations for a more accurate assessment of behaviour of reinforced concrete structures and prediction of their durability. Experimental and analytical modelling of formation and development of such cracks is extremely complicated.

Modelling difficulties of formation and development of longitudinal cracks can be avoided only if relevant backgrounds of kinetics of cracking processes are accepted [1, 7-9].

\section{Physical model of longitudinal crack formation and development}

Two alternatives are known for modelling formation of longitudinal cracks:

- cross-section of reinforcing bar is treated as a round hole and the hole contour is loaded by uniformly distributed ultimate rust pressure;

- around a rusting reinforcing bar there are relevant strains of concrete.

For creating crack formation physical model according to the first alternative the following assumptions are applied (Fig 1 a [1]):

- member zone with corroding reinforcement is treated conventionally as a plate of unit thickness and of unlimited dimensions with weakening at reinforcing bar location by round hollow (artificially cut) at the contour of which the first small radial cracks form;

- at the action of limit pressure $p_{0}$ of rust perpendicularly to $x$ axis radial cracks are symmetrical in respect to the centre of the cut, the total their and cut length $2 l_{0}=2 r+2 \Delta r,(\Delta r \ll r)$ and thickness $\delta_{\min }$ do not influence the beginning of cracks (especially if $\delta_{\min } \geq 2 r$ );

- concrete cover of reinforcement cracks when $\Delta l=l_{c r}$ (where $l_{c r}$ is the critical crack length); 
- when concrete is cracking close to the cut contour it is possible to apply criteria of the linear mechanics of fracture.

Limit rust pressure $p_{0}$ can be calculated by formula:

$$
K_{l c} \sqrt{\pi l_{0}}=\int_{-l_{0}}^{l_{0}} \frac{p_{0}(x) \sqrt{l^{2}-x^{2}}}{l-x} d x
$$

where $K_{I c}-$ critical coefficient of stress intensity at the top of crack. This coefficient characterizes concrete cracking resistance (material constant).

If $p_{0}(x)=p_{0} \sqrt{r^{2}-x^{2}} / r$, from the equation (1) rust limit pressure at the beginning of cracking can be expressed as follows:

$$
p_{0}=\frac{K_{l c} \sqrt{\pi l_{0}}}{1.67 r+0,33 r^{3} / l_{0}^{2}} .
$$

If $l_{0} \approx r$, pressure $p_{0}=1.25 K_{l c} / \sqrt{2 r}$.

$a$
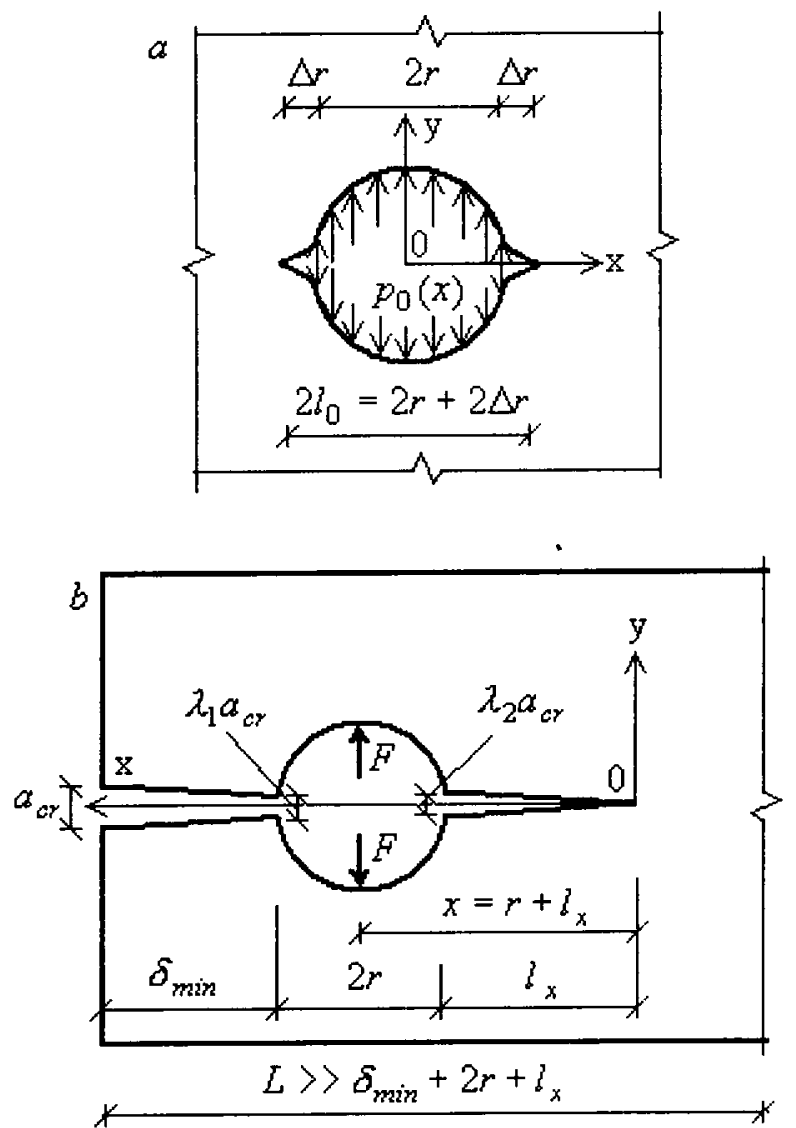

Fig 1. Schemes of physical models of crack formation (a) and development (b)

Due to the time factor influence on concrete cracking resistance the material constant has to be diminished $\sqrt{1+2 E_{b}\left(1-v^{2}\right) C(\infty, \tau)}$ times [7], where $E_{b}$ is the elasticity modulus of concrete, $v$ - Poisson's ratio, $C(\infty, \tau)-$ specific creep of concrete.
Physical model of crack development (Fig 1 b) after concrete cover has cracked is based on the following assumptions:

- at the cut contour perpendicularly to the $x$ axis two equal limit pressure resultants $F$, but of opposite directions, act and subject macro crack to stable development into cross-section;

- longitudinal crack and cylindrical cut is assumed as one macrocrack which length is equal to $l_{0}$ and circular cut has no influence on crack further development;

- crack width at the cut contour is proportionally equal to the distance up to vertex of a crack.

Resultant force of limit pressure $P$ can be calculated by formula:

$$
\begin{aligned}
& F=2 p r t=K_{I c} t \sqrt{0,5 \pi x} \psi\left(\xi_{1}, \xi_{2} \ldots\right)= \\
& =1.25 K_{I_{c}} t \sqrt{r+l_{x}} \psi\left(\xi_{1}, \xi_{2} \ldots\right),
\end{aligned}
$$

where $t$ is member thickness, $\psi\left(\xi_{1}, \xi_{2} \ldots\right)$ - function to take into consideration influence of scale factors for the value of limit pressure. Decrease of $K_{l c}$ coefficient due to concrete creep has also to be evaluated.

If longitudinal cracks cross several reinforcing bars, it is possible to model their formation and development under the same assumptions. So dependence of limit rust pressure and crack parameters can also be established [1].

\section{Numerical model of longitudinal crack formation and development}

A modern finite element method computer program was used for analysis of longitudinal crack formation and development [10]. The analysis was carried out under plain strain assumption $[8,9]$. Non-linear elastic model was used. Plastic deformations and descending stress/ strain diagram part of concrete were evaluated in this model (Fig 2). Mathematical expression of the diagram in case of concrete compression was applied according to the recommendations of code of practice [11]. For tensioned concrete the following equation was used:

$$
\frac{\sigma_{b t}}{R_{b t}}=2 \eta-\eta^{2}
$$

where

$$
\eta=\frac{\varepsilon_{b t} E_{b}}{2 R_{b t}},
$$

$\sigma_{b t}$ is concrete tensile stress, $R_{b t}$ - ultimate tensile stress of concrete, $\varepsilon_{b t}$ - concrete tensile strain.

According to the non-linear elastic model, concrete stresses can be expressed as follows:

$$
\sigma=\left[D_{\mathrm{sec}}\left(E_{\mathrm{sec}}, v\right)\right] \varepsilon,
$$

where $D_{\mathrm{sec}}$ is concrete secant matrix, $E_{\mathrm{sec}}$ - concrete secant modulus, $v$ - Poisson's ratio. 


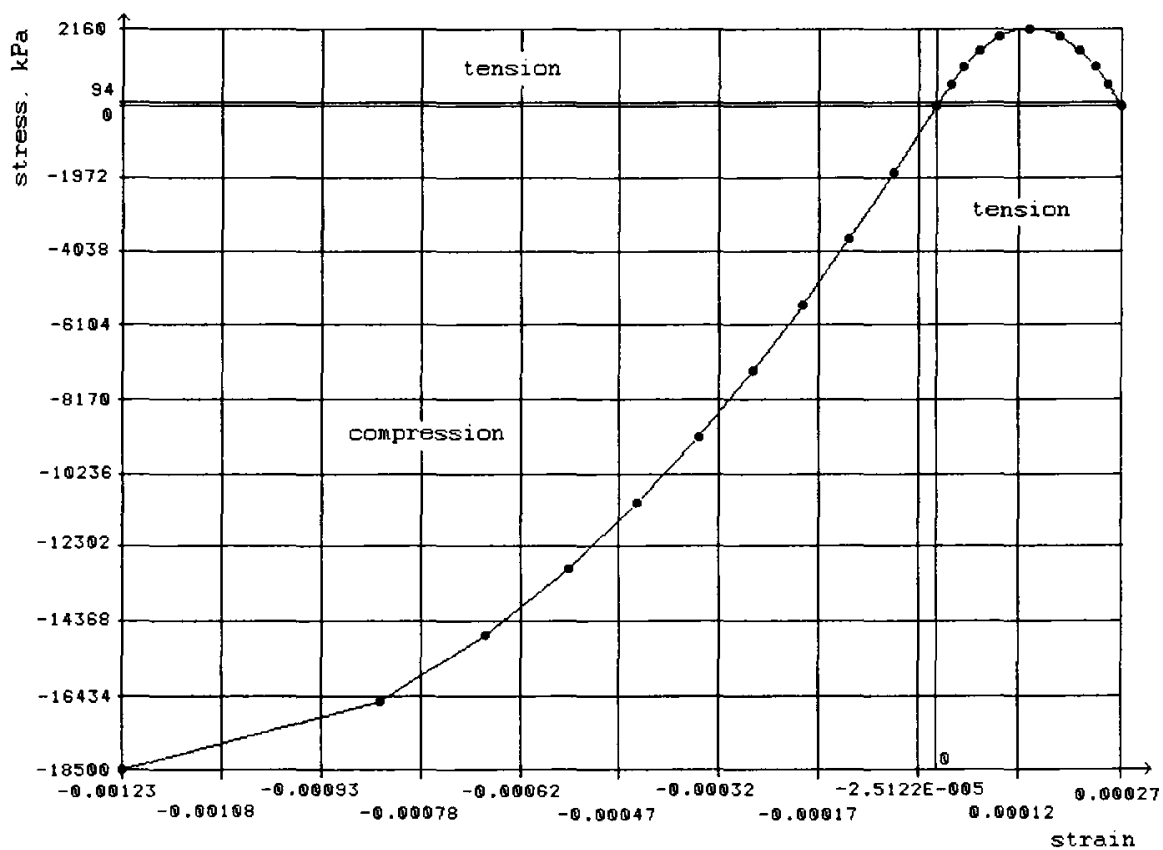

Fig 2. Stress-strain curve of concrete non-linear elastic model used in FEM analysis of crack formation and development

The total strain $\varepsilon$ vector is used to compute the effective strain $\varepsilon_{e f}$ :

$$
\begin{aligned}
& \varepsilon_{e f}=\underset{(1+v)(1-2 v)}{1-v}\left(\varepsilon_{x}^{2}+\varepsilon_{y}^{2}\right)+ \\
& 2 v \\
& (1+v)(1-2 v) \\
& \varepsilon_{x} \varepsilon_{y}+\frac{1}{2(1+v)} \gamma_{x y}^{2},
\end{aligned}
$$

where $\varepsilon_{x}, \varepsilon_{y}$ is linear strains in two mutually perpendicular directions, $\gamma_{x y}$ - angular strain.

Concrete secant modulus for each finite element can be calculated by formula:

$$
E_{\mathrm{sec}}=\frac{E_{\mathrm{sec}, c}+E_{\mathrm{sec}, t}}{2}+\Theta \frac{E_{\mathrm{sec}, c}-E_{\mathrm{sec}, t},}{2},
$$

where $E_{\mathrm{sec}, c}, E_{\mathrm{sec}, t}$ is concrete secant modulus in case of compression and tension respectively, $\Theta$ - ratio computed by using equation:

$$
\begin{aligned}
& \Theta=\frac{\varepsilon_{v}}{\varepsilon_{e f}(1-2 v)}, \\
& -1 \leq \Theta \leq 1
\end{aligned}
$$

where $\varepsilon_{v}$ is concrete volume strain.

Computer models for analysis of longitudinal crack formation and development were composed in such way that the finite element dimensions in the zones of the highest stresses were small. So open cracks were ready to model. Computation of each specimen was performed many times with gradual increase in effect of imitated pressure due to reinforcement corrosion. If the principal stress in any finite element exceeds tensile concrete strength or tensile strain exceeds the maximum value, it is assumed that cracking forms in the place which is included in the model for the next computation stage.

\section{Analysis of crack formation and development}

Experimental investigations of S. Williamson [12] were used for crack formation analysis. In Williamson's tests, $150 \times 150 \times 150 \mathrm{~mm}$ concrete cubes with 2 hollow cylinders of $8 \mathrm{~mm}$, or $16 \mathrm{~mm}$ diameter in its sides were tested. Oil pressure was applied to the internal surface to simulate the expansive behaviour of steel corrosion products. Characteristics of concrete cubes and crack failure patterns are included in table. Finite element method (FEM) and non-linear elastic model were also used for analysis of concrete cover cracking.

If pressure is applied perpendicularly to the whole contour pattern of specimens, crack fracture according to the FEM analysis results is analogous with those determined experimentally. If ratio $\delta_{\min } / d \leq 1$, the beginning of concrete cracking by FEM analysis results nearly coincides with the fracture of $\delta_{\min }$ thickness concrete cover. In this case crack development is unstable. Pattern of concrete fracture shows that if ratio $\delta_{\min } / d$ is small inclined cracks have a greater opportunity to appear. If ratio $\delta_{\min } / d$ is greater, limit pressure of concrete cracking is also greater (Fig 3).

If pressure is applied only in axis direction (Fig 1 a), FEM analysis results show that flexural cracks prevail in all cases. However if ratio $\delta_{\min } / d \leq 1$ cracks are unstable and their critical length $l_{c r}=\eta d_{\max }$, where $d_{\max }$ - maximum size of concrete coarse aggregate, $\eta=1,2 \ldots 1,7$ - coefficient by which kind of aggregate is taken into consideration [1]. According to FEM analysis results, change of critical crack length is approximately proportional to the ratio $\delta_{\min } / d$, ie $l_{c r} \approx \eta d_{\max } \delta_{\min } / d$. 
Experimental data of concrete crack formation [12] and comparison of calculated ultimate pressure values with experimental ones

\begin{tabular}{|c|c|c|c|c|c|c|c|c|c|}
\hline$\delta_{\min }$ & $\begin{array}{c}d: \\
m m\end{array}$ & $\frac{\delta_{\min }}{d}$ & $\begin{array}{l}R_{b t} \\
M P_{a}\end{array}$ & $\begin{array}{l}E_{b} \\
M P_{a}\end{array}$ & $\begin{array}{c}\text { Partern of specimen } \\
\text { fracture }\end{array}$ & $\begin{array}{l}p_{0, \max } \\
\mathrm{wPa}\end{array}$ & $\begin{array}{l}\text { Pattern of specimen } \\
\text { fracture by FEM } \\
\text { analysis results }\end{array}$ & $\frac{P_{0, c a l l}}{P_{0, m a x}}$ & $\frac{P_{0, \text { car } 2}}{p_{0, \text { max }}}$ \\
\hline 4 & 8 & \multirow[t]{2}{*}{0,5} & 2,16 & 31200 & \multirow{2}{*}{$\underbrace{a}_{x \rightarrow 150}]_{x}^{\infty}$} & 4,15 & \multirow{2}{*}[\begin{array}{c}{360}\\
{36}\end{array}]{} & 1,24 & 0.67 \\
\hline 8 & 16 & & 3,14 & 39750 & & 3.30 & & 1.49 & 0,91 \\
\hline 8 & 8 & \multirow[t]{2}{*}{1} & 2,16 & 31200 & \multirow{2}{*}{ 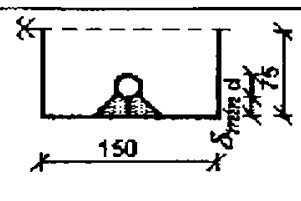 } & 7,42 & \multirow{2}{*}{ 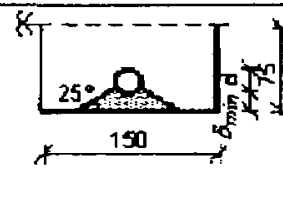 } & 0,69 & 0.63 \\
\hline 16 & 16 & & 3.14 & 39750 & & 6.8 & & 0,73 & 0,71 \\
\hline 16 & 8 & 2 & 2,16 & 31200 & 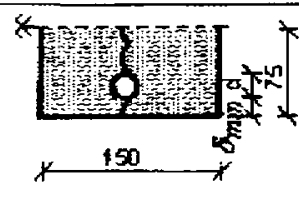 & 13,10 & 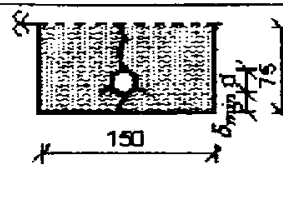 & 0,39 & 0,38 \\
\hline
\end{tabular}

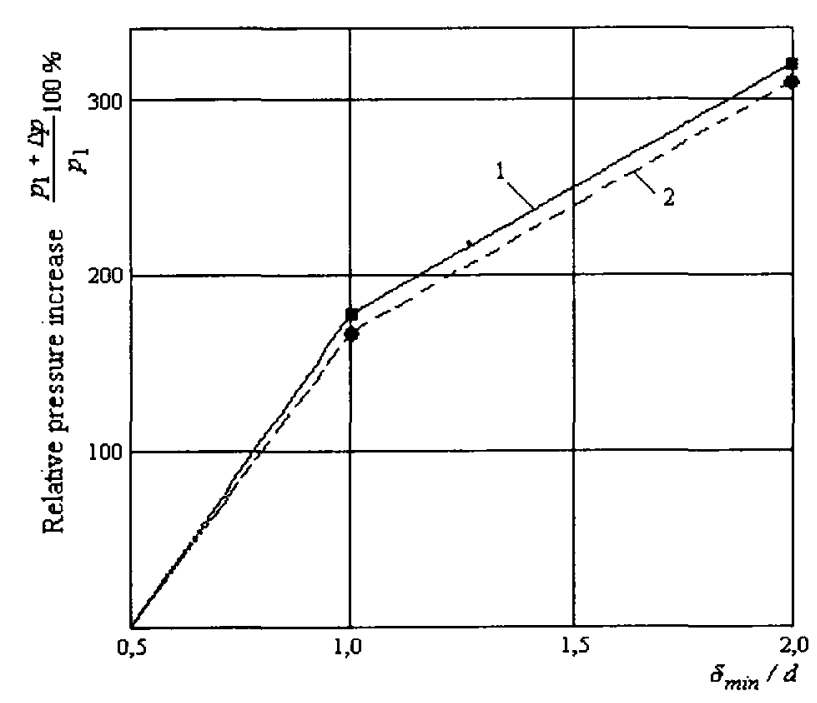

Fig 3. Relative pressure increase depending on ratio $\delta_{\min } / d$ if concrete tensile strength $R_{b t}=2,16 \mathrm{MPa}$ : 1 - experimental data [12], 2 - FEM computed results $\left(p_{1}-\right.$ pressure if ratio $\left.\delta_{\min } / d=0,5\right)$

Crack formation pressure $p_{0, c a l 2}$ applied perpendicularly to the cut contour and defined by FEM was compared with the experimental pressure $p_{0, \max }$ (Table). Values of limit pressure $p_{0, c a l 2}$ in comparison with experimental $p_{0 . \max }$ values decrease when increasing $\delta_{\min } / d$ ratio. It is because with the increase of this ratio the difference between limit pressure at the cracking start (it corresponds to $p_{0, c a l 1}$ and $p_{0, c a l 2}$ values) and experimental $p_{0, \max }$ pressure at the stage of complete fracture of cubes actually increases. Relative increases in limit pressures (Fig 3) calculated by FEM and determined experimentally are very close.

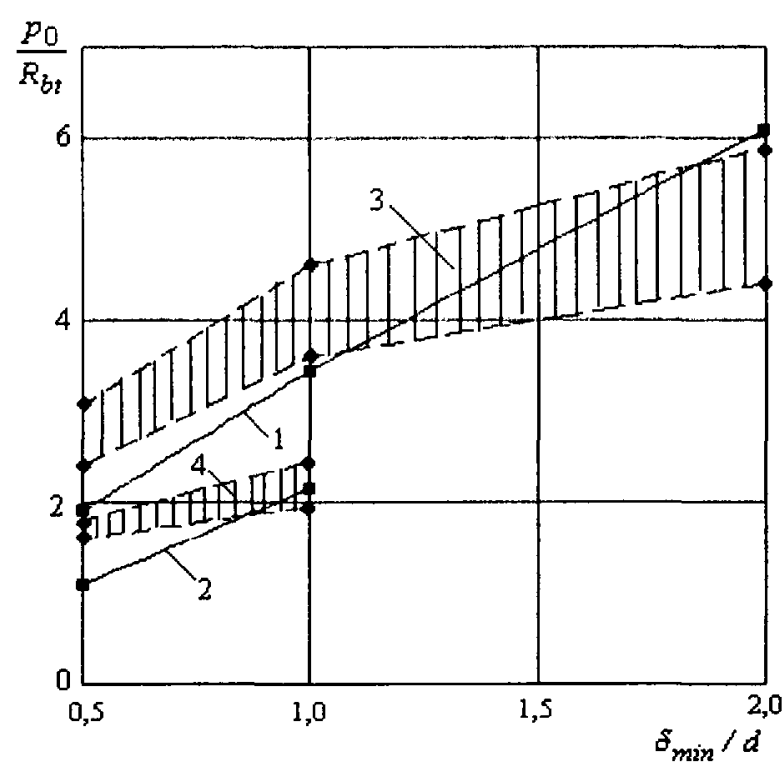

Fig 4. Change of concrete cover cracking pressure depending on ratio $\delta_{\min } / d: 1$ is experimental data [12] if $R_{b t}=2,16 \mathrm{MPa} ; 2$ - experimental data [12] if $R_{b t}=3,14 \mathrm{MPa} ; 3$ and 4 - zones of pressure values calculated by (2)

The analogical results are obtained having calculated limit pressure $p_{0 . c a l l}$ by (2) and accepting crack length $l_{0}=r$. If ratio $\delta_{\min } / d=0,5$, pressure $p_{0, c a l l}$ values are greater as they calculated allowing flexural cracks and not regarding inclined cracks. With the purpose to get more precise $p_{0, c a l l}$ values it is necessary to evaluate the increase of limit pressure at which cracks of critical length appear. For this purpose it is necessary to know concrete kind and size of coarse aggregate of the tested cubes [12]. Such data are not present. As thickness of 
concrete cover to reinforcement $\delta_{\min }=4 \mathrm{~mm}$, it is definitely possible to consider size of coarse aggregate $d_{\max } \leq 4 \mathrm{~mm}$. Therefore the critical length of unstable crack $l_{c r} \approx(1.2 \ldots 1.7)(2 \ldots 4) \approx 3,0 \ldots 7,0 \mathrm{~mm}$. According to the proposed method [1] critical width of crack at its vertex $\delta_{c}=0,00012 a \sqrt[3]{d}$, where $a=\delta_{\min }+r=8 \mathrm{~mm}$, $d=2 r=8 \mathrm{~mm}$. Constant $K_{l c}=\sqrt{E_{b} R_{b t} \delta_{c} /\left(1-v^{2}\right)}$ was calculated and zone of variation of pressure $p_{0}$ causing fracture of specimens was defined by (2).

As it is visible from the diagram of pressure variation (Fig 4), experimental values of pressure variation in an interval $\delta_{\min } / d=1 \ldots 2$ are in calculated by (2) zone of change of pressure values. If ratio $\delta_{\min } / d=0,5$, calculation of pressure $p_{0}$ was performed taking into account the minimum length of critical crack $\left(l_{c r}=0\right.$ and $\left.l_{c r}=3 \mathrm{~mm}\right)$

\section{Remarks and conclusions}

1. Numerical model described in section 3 is suitable for analysis of longitudinal crack formation and development in concrete cover to rusting reinforcement bar. This model correctly evaluates the character of concrete cracking due to reinforcement corrosion and allows making more accurate the assumptions for physical model of crack formation.

2. Physical model of longitudinal crack formation (Fig 1 a) correctly evaluates the main cracking tendencies of concrete cover to reinforcement if ratio $\delta_{\min } / d \geq 1$. Concrete structure and properties, character of rust pressure, parameters $\delta_{\min }$ and $d$ influence crack formation and development in concrete cover.

3. If ratio $\delta_{\min } / d \geq 1$, rust pressure can be applied only in $y$ axis direction (Fig 1 a). Crack development into the section after concrete cover to reinforcement has cracked can be evaluated by physical model in which rust pressure applied in $y$ axis direction is changed by resultants of the pressure.

\section{References}

1. Jokūbaitis V., Kamaitis $Z$. Cracking and repair of reinforced concrete structures (Gelžbetoninių konstrukcijų pleišejjimas ir remontas). Vilnius: Technika, 2000. 155 p (in Lithuanian).

2. Kovacs T. Deterioration of reinforced concrete repair mortar layers. Periodica Polytechnica, ser. Civ. Eng., 44, 2, 2000, p 197-206.

3. Sulaimani G. J., Kaleemullah M., Basunbul I. A. Influence of Corrosion and Cracking on Bond Behavior and Strength of Reinforced Concrete Members. ACI Structural Journal, 87, 2, 1990, p 220-231.

4. Clark L. A., Saifullah M. Effect of Corrosion on Reinforcement Bond Strength. In: Proceedings of $5^{\text {th }}$ International Conference on Structures Faults and Repair, Vol 3, 1993, p 113-119.

5. Rasheeduzzafar A., Saadoun S. S., Gahtani A. S. Corrosion Cracking in Relation to Bar Diameter, Cover and Concrete Quality. Journal of Materials in Civil Engineering, 4, 4, 1992, p 327-342.

6. Williamson S., Clark L. A. Influence of Cover Concrete Quality on the Effect of Reinforcement Corrosion. In: Proceedings of the 7 th International Conference Conference on Structures Faults and Repair, Vol 23, 1997, p 441-446.

7. Piradov K. A., Guzeev E. A. Physical and mechanical fundamentals of durability of concrete and reinforced concrete. Concrete and reinforced concrete (Бетон и железобетон), No 1, 1998, p 25-26 (in Russian).

8. A. D. Jefferson, H. D. Wright. Stepped Softening Function for Concrete Fracture in Finite Element Analysis. Computers \& Structures, 41, 2, 1991, p. 331-344.

9. Kupfer H. B., Hilsdorf H. K., Rusch H. Behaviour of Concrete under Biaxial Stress. Journal $A C I, 66,8$, Aug 1969, p 151-159.

10. COSMOS/M. Finite element analysis system. Basic FEA System. User guide. Structural Research \& Analysis Corp., Los Angeles, 1995. $760 \mathrm{p}$.

11. Eurocode 2: Design of concrete structures. Part 1: General rules and rules for buildings, 1991. $259 \mathrm{p}$.

12. Du .Y. G., Chan A. H. C., Williamson S., Clark L. A. FEM Analysis of Concrete Cracking due to Steel Corrosion. Proc., EURO-C 1998 - Computational Modeling of Concrete Structures, Badgastein, Austria, March 31 - April 3, 1998, p 481-490 